\title{
Hysteresis of boiling for different tunnel-pore surfaces
}

\author{
Robert Pastuszko ${ }^{1, a}$, Magdalena Piasecka ${ }^{1}$ \\ ${ }^{1}$ Kielce University of Technology, Department of Mechanics, Al. Tysiaclecia P.P.7, 25-314 Kielce, Poland
}

\begin{abstract}
Analysis of boiling hysteresis on structured surfaces covered with perforated foil is proposed. Hysteresis is an adverse phenomenon, preventing high heat flux systems from thermal stabilization, characterized by a boiling curve variation at an increase and decrease of heat flux density. Experimental data were discussed for three kinds of enhanced surfaces: tunnel structures (TS), narrow tunnel structures (NTS) and mini-fins covered with the copper wire net (NTS-L). The experiments were carried out with water, R-123 and FC-72 at atmospheric pressure. A detailed analysis of the measurement results identified several cases of type I, II and III for TS, NTS and NTS-L surfaces.
\end{abstract}

\section{Introduction}

Hysteresis phenomena manifest themselves more clearly during boiling on enhanced surfaces than on plain, smooth surfaces. Experimental boiling curves with hysteresis have different trends, depending on thermal and geometrical parameters of the enhancement structure and boiling liquid physical properties [1].

Wójcik [1] as well as Poniewski and Thome [2] classified four main hysteresis types:

- Nucleation hysteresis - connected with the phenomenon of temperature overshoot (TOS) or zero boiling crisis. It is well described in the literature, both for smooth surfaces and developed microsurfaces.

- Type-I hysteresis or reverse hysteresis loop, which is connected with the phenomenon of intra-layer (or internal) boiling crisis, is characterized by the decrease in heat transfer coefficient after the decrease in heat flux.

- Type-II hysteresis or simple hysteresis loop - the heat transfer coefficient increases as the heat flux diminishes, prior to the latter reaching the maximum.

- Type-III hysteresis is characterized by first a decrease and later an increase in the heat transfer coefficient for the heat flux decreasing after reaching the critical heat flux.

Boiling incipience and nucleation hysteresis is not only a general problem in boiling itself, but also a practical one in the evaluation of the safety of equipment ranging from electronics to nuclear reactors. It is known, that under certain conditions, there can occur a considerable rise in wall temperature above the saturation point before boiling begins. This "temperature overshoot" called "superheated excursion" or "nucleation hysteresis" is conspicuous when highly wetting dielectric fluids (e. g. refrigerants) are used. This kind of hysteresis occurs in the flow through channels of small dimensions (minichannels) and was described in detail in $[3,4]$. Due to using liquid crystal thermography in research it was possible to observe changes in the heating surfaces temperature and analyse "boiling front" and "nucleation hysteresis".

This article summarizes the results of the analysis of boiling hysteresis for investigations conducted on three types of surfaces with subsurface tunnels. The measurement data for the three types of working fluid used in the studies were taken from $[5,6,7,8]$.

\section{Experimental research}

\subsection{Investigated surfaces}

\subsubsection{TS surfaces}

The specimens with the tunnel structures (TS) form a square with $27 \mathrm{~mm}$ long sides $\left(w_{\mathrm{f}}\right)$. The three main fins, $5 \mathrm{~mm}$ in height $\left(h_{\mathrm{f}}\right)$, thickness $5 \mathrm{~mm}\left(\delta_{\mathrm{f}}\right)$, interfins space 5 $\mathrm{mm}(\mathrm{s})$, were modified to include tunnels on the vertical surfaces and in the horizontal inter-fin spaces. The perforated copper foil was sintered to the machined surfaces (figure 1) creating a structure of combined U-shaped tunnels. Parameters of TS surface are shown in table 1.

The investigated tunnel surfaces were designed to allow the separation of the liquid suction sites (pores in vertical tunnel) from growing bubbles at tunnel outlet [5].

${ }^{a}$ Corresponding author: tmprp@tu.kielce.pl 
Table 1. TS samples code and specifications

\begin{tabular}{llllll}
\hline $\begin{array}{l}\text { Sample code } \\
\mathbf{T S}, \boldsymbol{h}_{\mathrm{f}}=\mathbf{5} \mathbf{~ m m}\end{array}$ & $\begin{array}{l}\text { pore } \\
\text { dia. } \\
\boldsymbol{d}_{\mathbf{p}}, \\
\mathbf{m m}\end{array}$ & $\begin{array}{l}\text { pore } \\
\mathbf{p i t c h}, \\
\boldsymbol{p}_{\mathbf{p}}, \\
\mathbf{m m}\end{array}$ & $\begin{array}{l}\text { horiz. } \\
\text { tunnel } \\
\text { depth, } \\
\boldsymbol{h}_{\text {tun }}, \\
\mathbf{m m}\end{array}$ & $\begin{array}{l}\text { tunnel } \\
\text { width } \\
\boldsymbol{w}_{\text {tun, }} \\
\mathbf{m m}\end{array}$ & $\begin{array}{l}\text { tunnel } \\
\text { pitch } \\
\boldsymbol{p}_{\text {tun }}, \\
\mathbf{m m}\end{array}$ \\
\hline $5-2.00-0.3$ & 0.3 & 0.6 & 1.6 & 1.3 & 2.00 \\
\hline $5-2.00-0.4$ & 0.4 & 0.8 & 1.6 & 1.3 & 2.00 \\
\hline $5-2.00-0.5$ & 0.5 & 1.0 & 1.6 & 1.3 & 2.00 \\
\hline $5-2.25-0.3$ & 0.3 & 0.6 & 1.6 & 1.3 & 2.25 \\
\hline $5-2.50-0.3$ & 0.3 & 0.6 & 1.6 & 1.3 & 2.50 \\
\hline
\end{tabular}

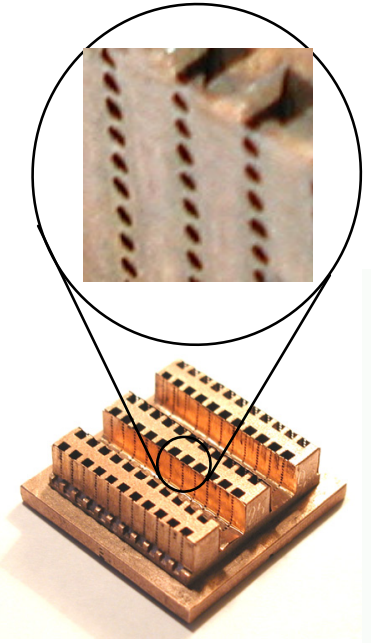

a)
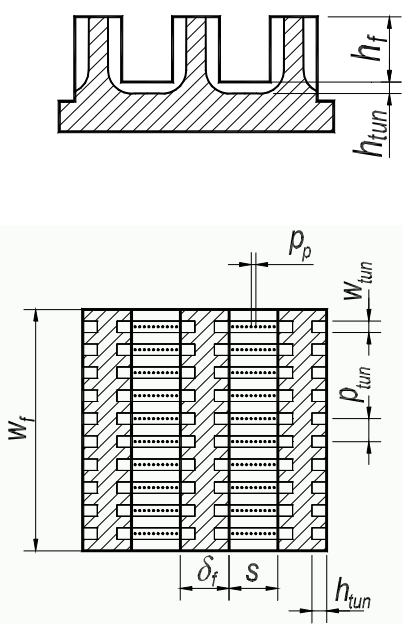

b)
Figure 1. Investigated TS surfaces: a) views of the sample with $10 \mathrm{~mm}$ high fins, b) cross sections [5].

\subsubsection{NTS surfaces}

The main fins, $5 \mathrm{~mm}$ in height, were thru-milled to form mini-fins with the width corresponding to the thickness of the base fins. Additionally, an array of combined tunnels was created, closed with the sintered perforated foil (figure 2). The constant parameters of the samples were as follows: main fin number: 3 , width of space between fins $(s): 5 \mathrm{~mm}$, fin thickness $\left(\delta_{\mathrm{f}}\right): 5 \mathrm{~mm}$. The other parameters of the NTS surfaces are shown in table 2:

Table 2. NTS samples code and specifications

\begin{tabular}{|c|c|c|c|c|c|}
\hline Sample code & \multirow{2}{*}{$\begin{array}{l}\text { pore } \\
\text { dia. } \\
d_{\mathrm{p}}, \\
\mathrm{mm}\end{array}$} & \multirow{2}{*}{$\begin{array}{l}\text { pore } \\
\text { pitch, } \\
p_{p}, \\
\text { mm }\end{array}$} & \multirow{2}{*}{$\begin{array}{l}\text { horiz. } \\
\text { tunnel } \\
\text { depth, } \\
h_{\text {tun, }} \\
\text { mm }\end{array}$} & \multirow{2}{*}{$\begin{array}{l}\text { tunnel } \\
\text { width } \\
w_{\text {tun, }} \\
\text { mm }\end{array}$} & \multirow{2}{*}{$\begin{array}{l}\text { tunnel } \\
\text { pitch } \\
p_{\text {tun, }} \\
\text { mm }\end{array}$} \\
\hline $\begin{array}{l}\text { NTS, } \quad h_{\mathrm{f}}=\mathbf{5} \\
\mathrm{mm}\end{array}$ & & & & & \\
\hline $5-0.6-0.3$ & 0.3 & 0.6 & 1.0 & 0.6 & 2 \\
\hline $5-0.6-0.4$ & 0.4 & 0.8 & 1.0 & 0.6 & 2 \\
\hline $5-1.0-0.3$ & 0.3 & 0.6 & 1.0 & 1.0 & 2 \\
\hline $5-1.5-0.3$ & 0.3 & 0.6 & 1.0 & 1.5 & 2 \\
\hline $5-1.5-0.4$ & 0.4 & 0.8 & 1.0 & 1.5 & 2 \\
\hline $5-1.5-0.5$ & 0.5 & 1.0 & 1.0 & 1.5 & 2 \\
\hline
\end{tabular}

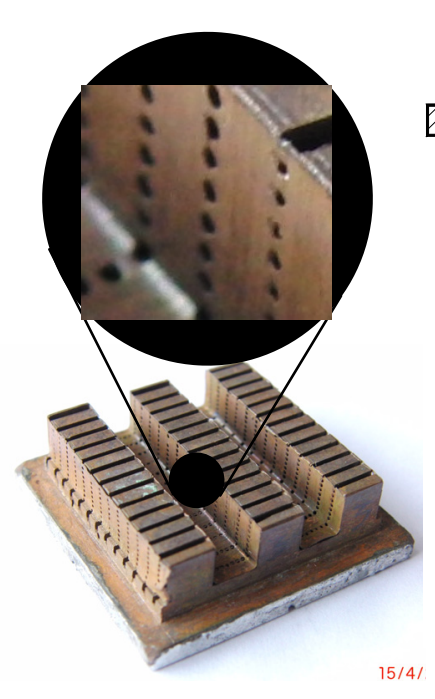

a)
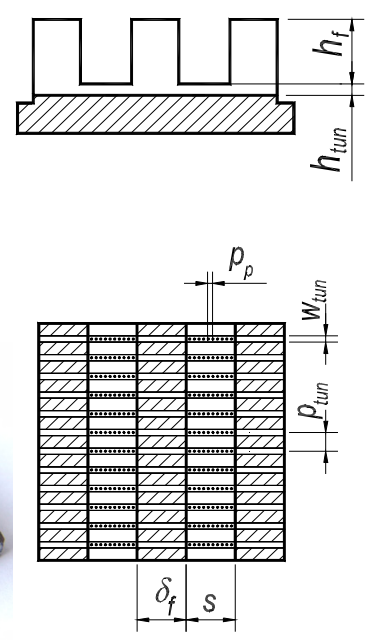

b)
Figure 2. Investigated NTS surfaces: a) views of the specimen with $5 \mathrm{~mm}$ high fins, b) cross sections [5].

\subsubsection{NTS-L surfaces}

These are structural surfaces formed by sintering the copper wire mesh made of $0.14 ; 0.2 ; 0.32 \mathrm{~mm}$ wire to the mini-fin tips. The copper specimens, square in shape with a side of $26.5 \mathrm{~mm}$, have $112 \mathrm{mini}$-fins and form a system of tunnels (figure 3). The parameters are presented in table 3 .

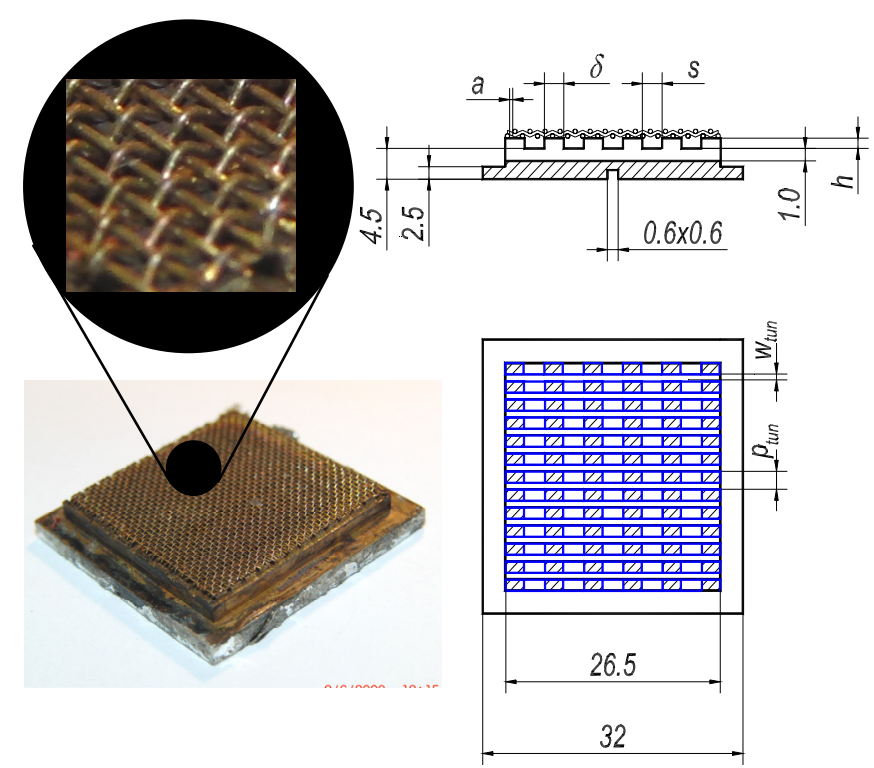

a)

b)

Figure 3. Investigated NTS-L surfaces: a) views of the specimen, b) cross sections. 
Table 3. NTS-L samples code and specifications

\begin{tabular}{|c|c|c|c|c|c|}
\hline $\begin{array}{l}\text { Sample } \\
\text { code } \\
\text { NTS-L } \\
\text { h=0.5 mm }\end{array}$ & $\begin{array}{l}\text { mini-fin } \\
\text { thickness } \\
\delta, \mathrm{mm}\end{array}$ & $\begin{array}{l}\text { inter- } \\
\text { fin } \\
\text { space } \\
s, \mathrm{~mm}\end{array}$ & $\begin{array}{l}\text { tunnel } \\
\text { width } \\
w_{\text {tun, }} \\
\text { mm }\end{array}$ & $\begin{array}{l}\text { tunnel } \\
\text { pitch } \\
p_{\text {tun, }} \\
\text { mm }\end{array}$ & $\begin{array}{l}\text { mesh } \\
\text { aperture } \\
a, \mathrm{~mm}\end{array}$ \\
\hline $0.5-0.6-0.3$ & 2 & 1.5 & 0.6 & 2 & 0.32 \\
\hline $0.5-0.6-0.4$ & 2 & 1.5 & 0.6 & 2 & 0.4 \\
\hline $0.5-0.6-0.5$ & 2 & 1.5 & 0.6 & 2 & 0.5 \\
\hline $0.5-0.6$ & 2 & 1.5 & 0.6 & 2 & -- \\
\hline
\end{tabular}

\subsection{Experimental set-up}

The experimental set-up designed for determining the boiling curves and heat transfer coefficients was composed of the following modules (figure 4):

A. the basic module interchangeable with the module for internal visualization;

B. the power module and the supplied electric power measurement;

C. the temperature measurement and data acquisition module;

D. the vapor cooling and condensate recovery module.

\section{Results}

\subsection{Type-I hysteresis}

Heat transfer coefficient decreases with decreased heat flux (after the critical heat flux density is reached). The boiling curve of R-123 for the NTS-5-0.6-0.3, as shown in figure 5, the boiling curve of R-123 for the TS-5-2.25-0.3 in figure 6

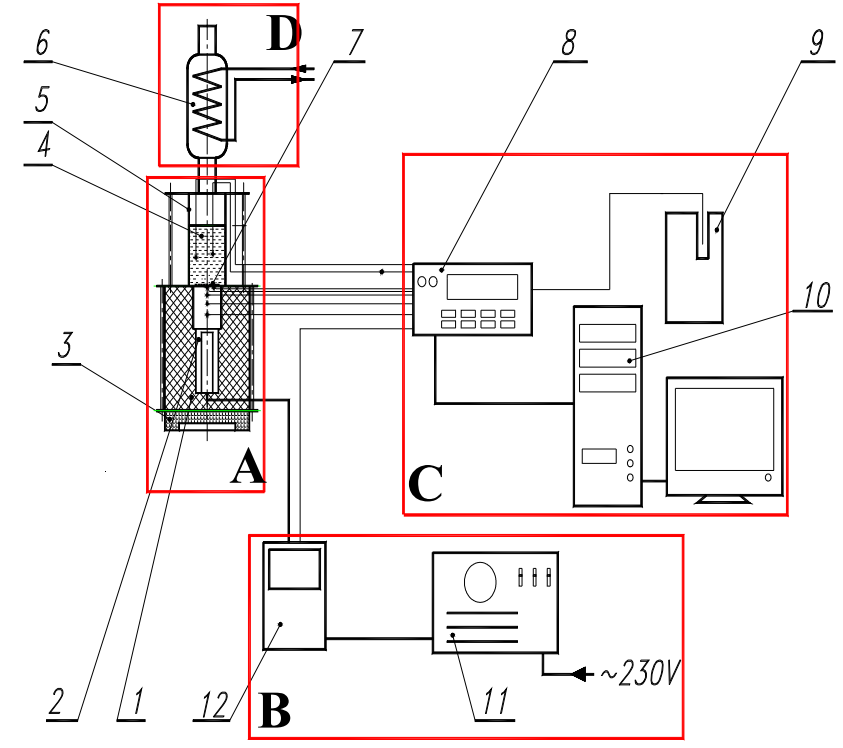

Figure 4. Measuring apparatus: 1 - insulation; 2 - copper bar with cartridge heater; 3 - Teflon casing; 4 - boiling liquid; 5 glass vessel; 6 - condenser; 7 - investigated sample; 8 - data logger $\&$ acquisition system; 9 - dry-well calibrator; 10 - PC; 11 power supply (transformer and fuses); 12 - wattmeter.

and the boiling curve of FC-72 on the NTS-L-0.5-0.6-0.3 (figure 7) represent the phenomenon of type-I hysteresis. This phenomenon can be explained, as in the case of porous structures, by an internal boiling crisis [9] associated with a low permeability of smallest-diameter pores.

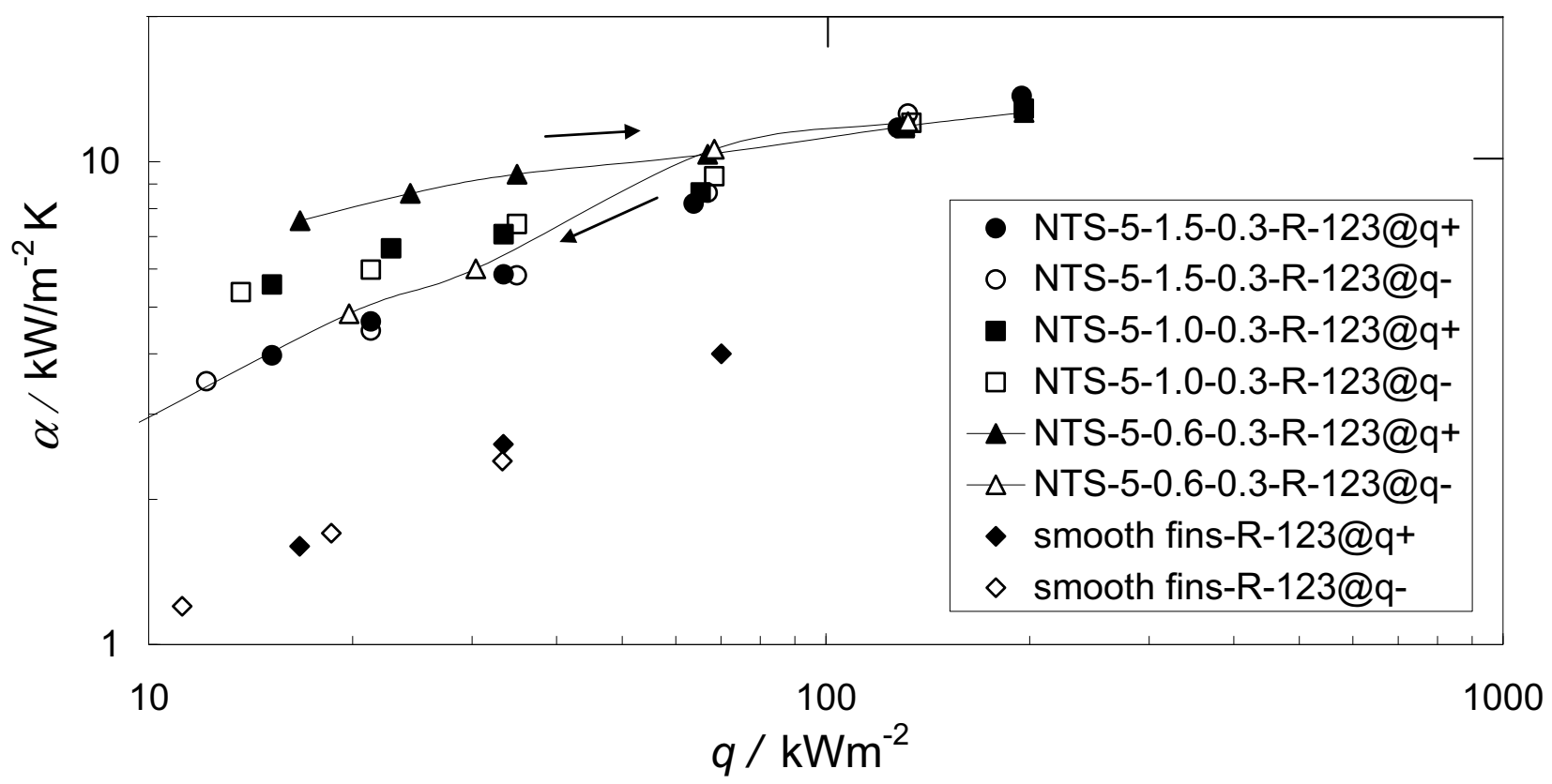

Figure 5. Boiling R-123 - type-I hysteresis for NTS-5-0.6-0.3. 


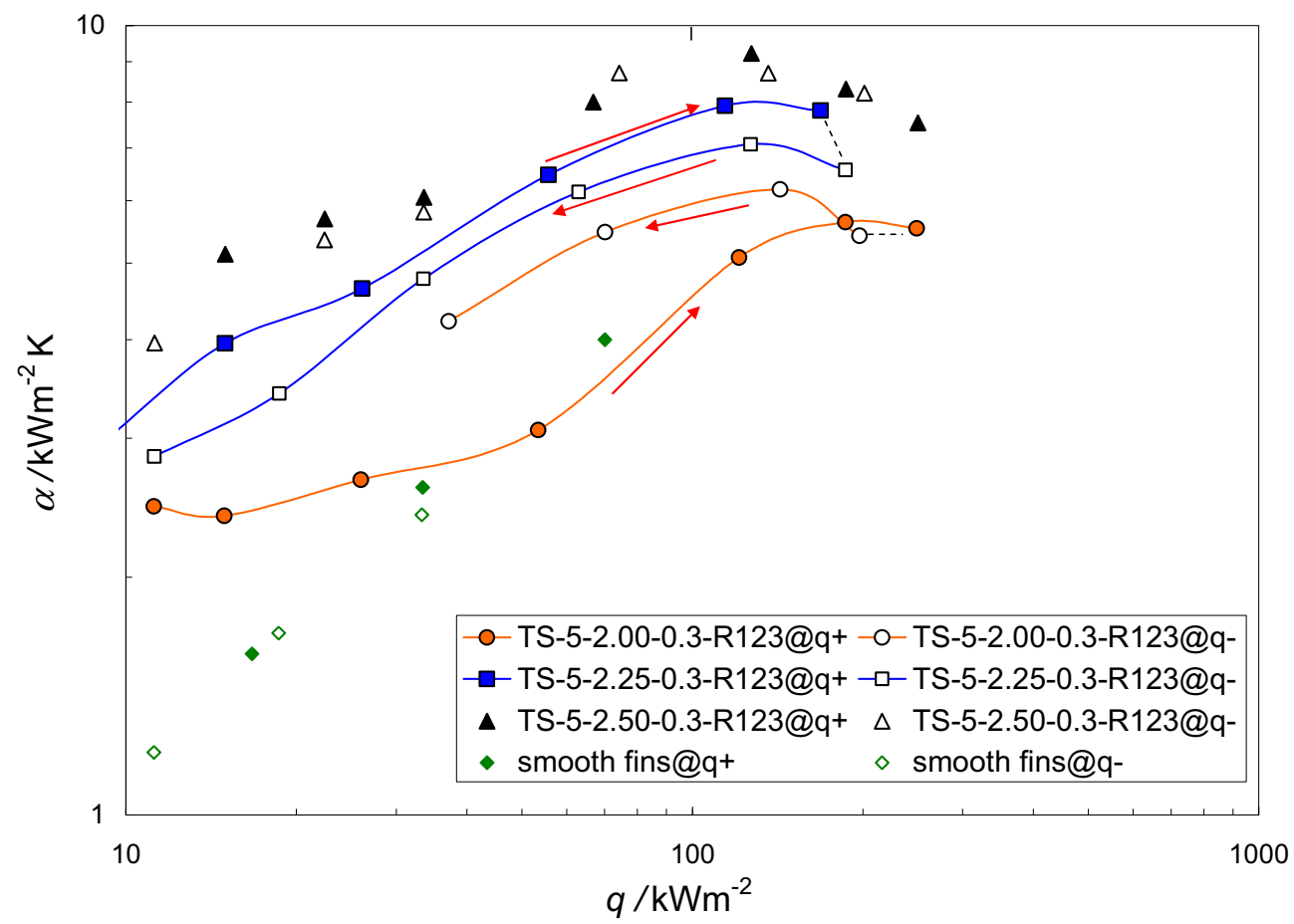

Figure 6. Boiling R-123, type-I hysteresis (TS-5-2.25-0.3) and type- II /III hysteresis (TS-5-2.00-0.3).

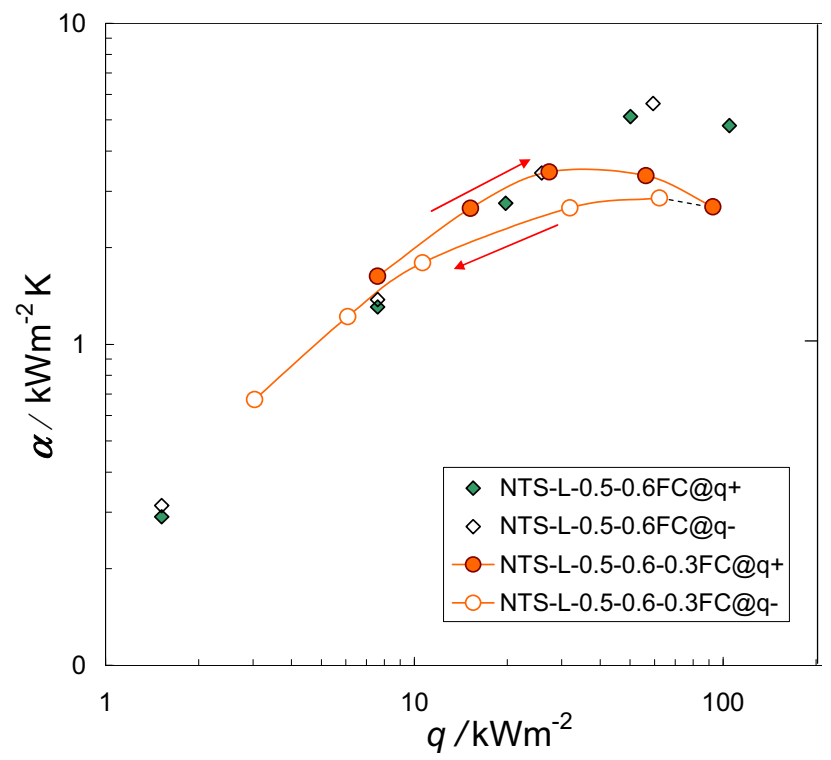

Figure 7. Boiling FC-72, type-I hysteresis (NTS-L-0.5-0.6-0.3).

The literature offers numerous hypotheses related to the mechanism of interlayer boiling crisis.

Ferrell and Allevitch [10] assumed that the boiling crisis on a porous surface starts when the capillary forces are incapable of maintaining liquid film next to the heat transfer surface. Afgan and Kovalev [9] claim that the interlayer boiling crisis begins when stable circulation of fluid to the heating surface is stopped by a porous layer. This happens when the accumulative drop in pressure at the vapor and liquid flow in the structure is higher than the pressure capillary gain [1].

Stable circulation is possible when:

$$
\Delta p_{k} \geq \Delta p_{v}+\Delta p_{l}
$$

where: $\Delta p_{k}$ is the capillary pressure in a porous structure; $\Delta p_{v}-$ is the resistance of vapor flow through the structure; $\Delta p_{l}-$ is the resistance of fluid flow through the structure.

Vapor and fluid flow rates increase with increased heat flux. For a certain heat flux value, sum $\Delta p_{v}+\Delta p_{l}$ is larger than $\Delta p_{k}$.

\subsection{Type-II hysteresis}

Heat transfer coefficient increases with decreased heat flux before the heat flux reaches its maximum density. Low hysteresis of this type was obtained for boiling water on the TS with pores $0.3 \mathrm{~mm}$ (figure 8) and the NTS with pores 0.3 and $0.4 \mathrm{~mm}$ (figure 9). Type-II hysteresis can be observed for boiling R-123 on the TS-52.00-0.3 (figure 6), assuming that the heat flux has been reduced prior to boiling crisis.

It can be presumed that at the highest heat flux densities, all vertical tunnel outlets on TS/NTS become active as do most of the horizontal tunnel pores (about 70 $-80 \%$ of total pore number for boiling water on the TS). Reduction of $q$ leads to a slow deactivation of active centers (pores), which results in higher nucleation sites densities at small superheats. Thus most active pores continue to act as active nucleation centers after decreasing the heat flux. As a results, the heat transfer coefficient increases with decreasing flux - e.g., with the NTS-5-1.5-0.3 (figure 9) at $q=30 \mathrm{~kW} / \mathrm{m}^{2}: \alpha(q-) \approx 1.4$ $\alpha(q+)$. 


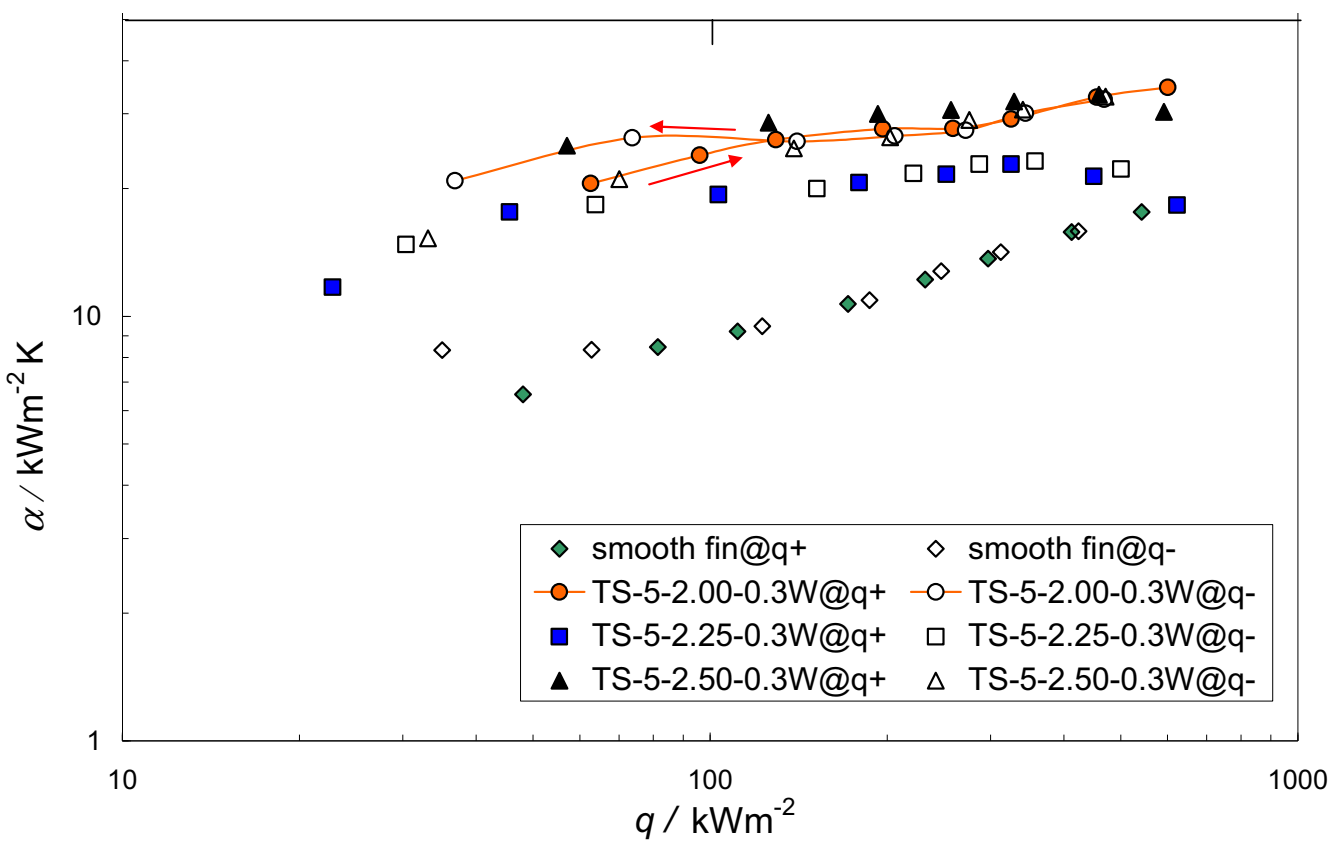

Figure 8. Boiling water on the TS-5-2.00-0.3 - type-II hysteresis.

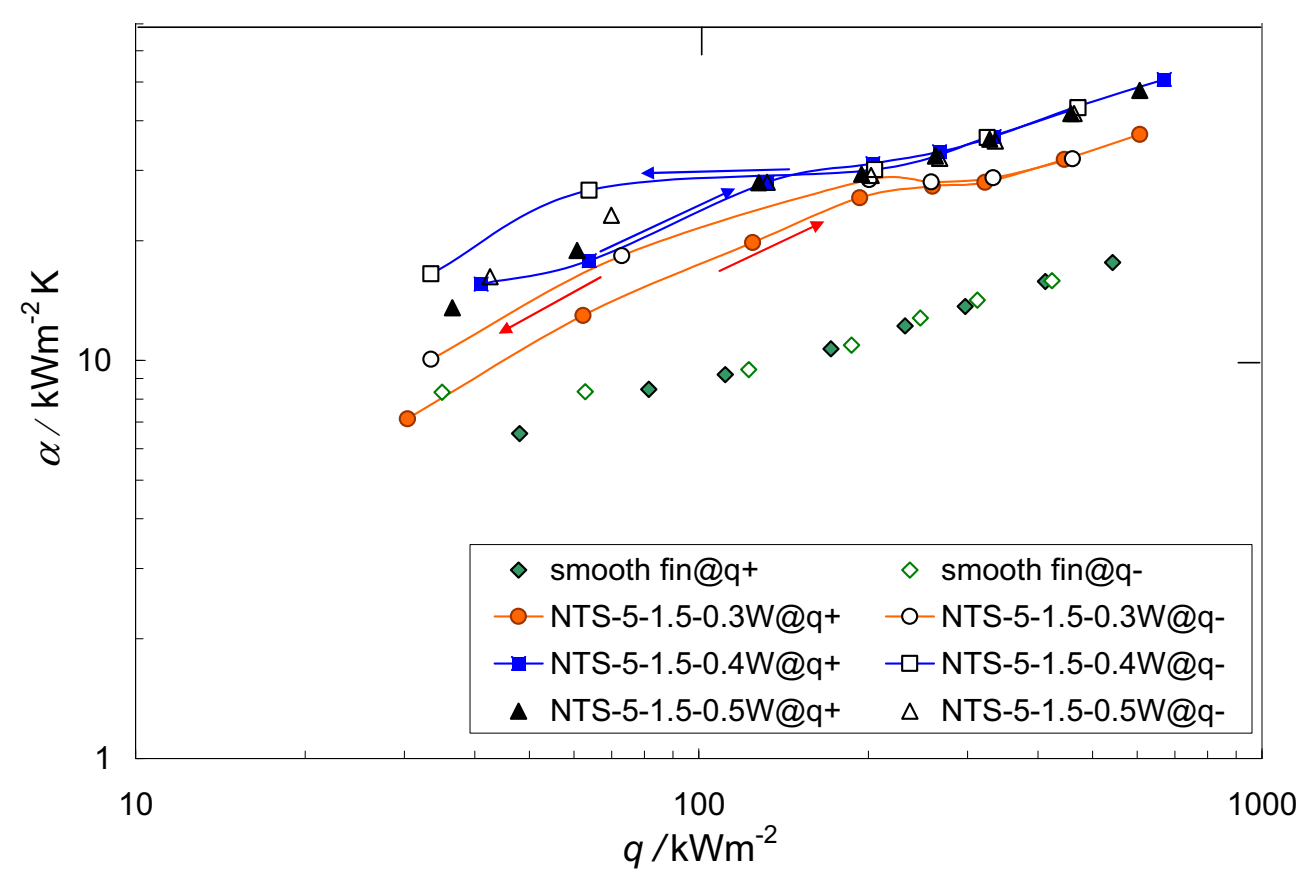

Figure 9. Boiling water on NTS-5-1.5-0.3 and NTS-5-1.5-0.4 - type-II hysteresis.

\subsection{Type-III hysteresis}

This rare phenomenon is characterized by a decrease of the heat transfer coefficient followed by its increase [1]. It occurs as the heat flux reaches its maximum density and starts decreasing. This may be attributed to the outflow of vapor, earlier than in the case of type-I hysteresis, and the dry-out of the tunnel. The R-123 boiling curve for the TS-5-2.00-0.3 (figure 6) can be considered type-III hysteresis when the heat flux decreases after boiling crisis.

Typical features of boiling R-123 on TSs ( $5 \mathrm{~mm}$ high main fins) with pores $0.3 \mathrm{~mm}$ in diameter (figure 6) include occurrence of different types of hysteresis for tunnel pitches 2 and $2.25 \mathrm{~mm}$, and absence of hysteresis when the pitch is increased to $2.5 \mathrm{~mm}$. 


\section{Conclusions}

The following detailed conclusions can be drawn:

- Several cases of types I, II and III hysteresis were recorded on surfaces investigated.

- Hysteresis most frequently occurs when: pores are 0.3 $\mathrm{mm}$ in diameter, fin height is $5 \mathrm{~mm}$ (TS/NTS) or 0.5 $\mathrm{mm}$ (NTS-L), tunnel width is $0.6 \mathrm{~mm}$ (NTS, NTS-L).

- The literature lacks analysis and models of hysteresis for tunnel-pore surfaces.

- Processes to which hysteresis may be attributed differ from those for capillary-porous surfaces; attempts can be made to use some elements of the hypotheses related to the mechanism of internal boiling crisis.

- For 150 boiling curves analyzed from 60 TS/NTS//NTS-L surfaces, hysteresis was identified in less than 10 cases $(<7 \%)$.

\section{Acknowledgments}

The research has been partially financially supported by the National Scientific Center granted on the basis of decision No. DEC-2013/09/B/ST8/02825.

\section{References}

1. T.M. Wójcik, Exp. Thermal Fluid Science 33, 397404 (2009)

2. M.E Poniewski, J.R. Thome, Nucleate boiling on micro-structured surfaces (Heat Transfer Research Inc., College Station, 2008)

3. M. Piasecka, Heat Mass Transf. 49, 261-271 (2013)

4. M. Piasecka, Int. J. Heat and Mass Transf. 66, 72488 (2013)

5. R. Pastuszko, Exp. Thermal Fluid Science 32, 15641577 (2008)

6. R. Pastuszko, Exp. Thermal Fluid Science 38, 149164 (2012)

7. R. Pastuszko, EPJ Web of Conferences 45, 01020 (2013)

8. R. Pastuszko, M. Piasecka, Journal of Physics: Conference Series 395, 012137 (2012)

9. N.W. Afgan, L.A. Jovic, S.A. Kovalev, V.A. Lenkov, Int. J. Heat Mass Transfer 28, 415-421 (1985)

10. J.K. Ferrell, J. Allevitch, Chem. Eng. Progress Symp. Ser., 66 (1970) 